Portland State University

PDXScholar

TREC Final Reports

Transportation Research and Education Center

(TREC)

4-2017

\title{
Design for an Aging Population
}

Trygve Faste

University of Oregon

Kiersten Muenchinger

University of Oregon

Follow this and additional works at: https://pdxscholar.library.pdx.edu/trec_reports

Part of the Civil Engineering Commons, Transportation Engineering Commons, and the Urban Studies and Planning Commons

Let us know how access to this document benefits you.

\section{Recommended Citation}

Faste, T. and Muenchinger, K. Design for an Aging Population. NITC-ED-986. Portland, OR: Transportation Research and Education Center (TREC), 2017. https://doi.org/10.15760/trec.167

This Report is brought to you for free and open access. It has been accepted for inclusion in TREC Final Reports by an authorized administrator of PDXScholar. Please contact us if we can make this document more accessible: pdxscholar@pdx.edu. 


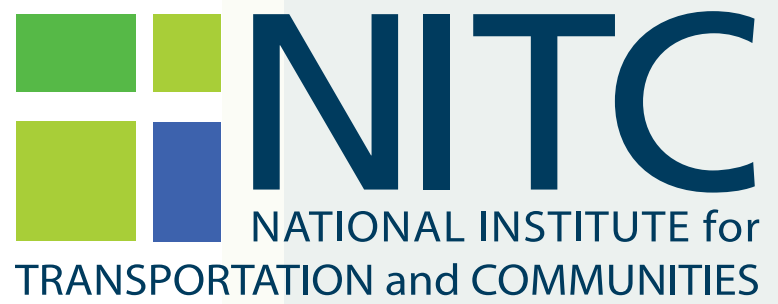

FINAL REPORT

Design for an Aging Population

NITCN-ED-986 $\quad$ April 2017

NITC is a U.S. Department of Transportation

national university transportation center.

= TREC 



\title{
DESIGN FOR AN AGING POPULATION DESIGN RESEARCH TOWARDS VIABLE BUS USE FOR AN AGING POPULATION
}

\author{
Final Report
}

NITC-ED-986

by

Trygve Faste \& Kiersten Muenchinger

University of Oregon

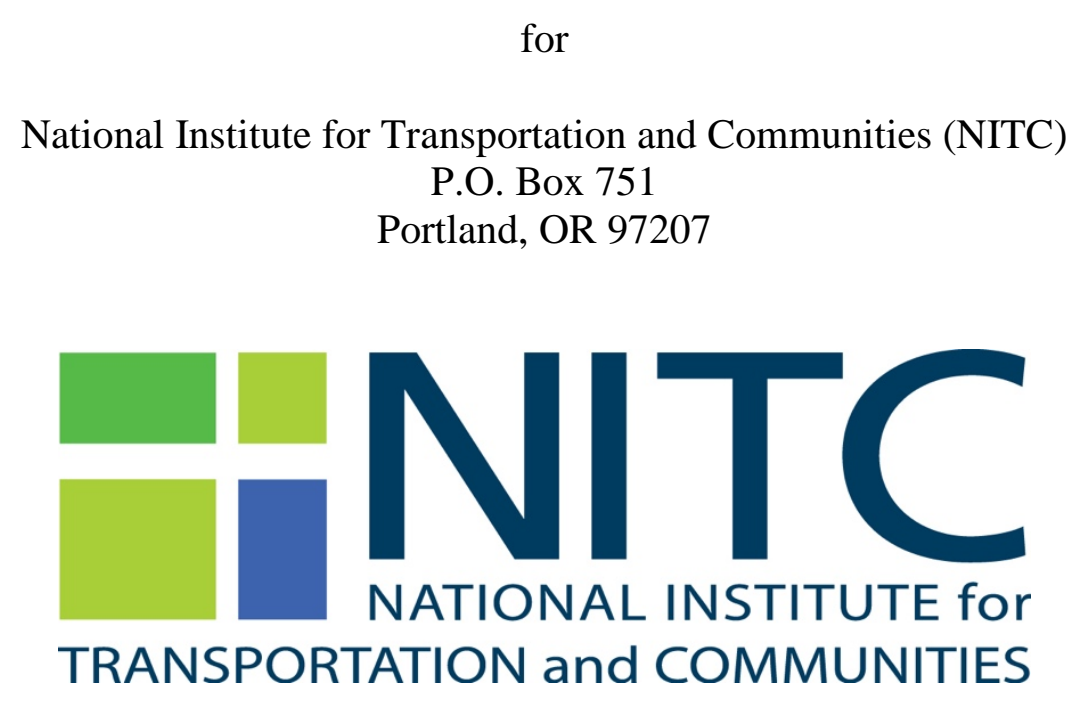

April 2017 




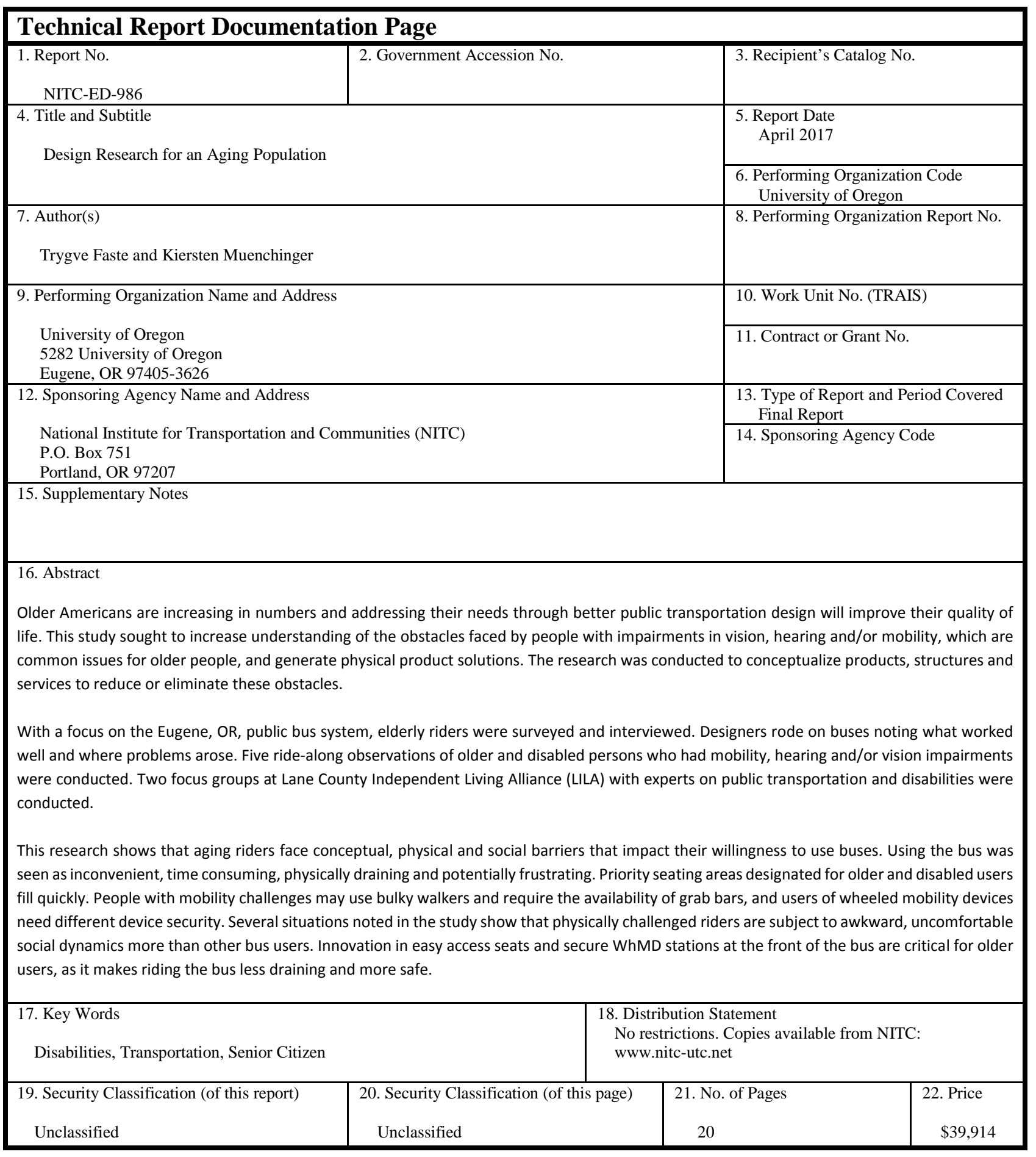





\section{ACKNOWLEDGEMENTS}

This study was funded by the National Institute for Transportation and Communities (NITC). The student design researchers involved in this project include Cara Anthieny, Elias Burch, Ching-Lu Chueh, Maleah Cooper, Andrew Eldredge, Kevin Elliott, Nathan Hemphill, Kinsey Johnson, Carly Keyes, Jack Koby, Brittany Lang, Sam Selbie, Connor Shimamoto, Morgan Snook, and James Tuttle. Kate Scott, the Community Program Analyst \& OAA Contract Manager for Senior and Disability Services, arranged meetings with the Disability Services Advisory Council and the Senior Services Advisory Council of the Lane Council of Governments. Andy Fernandez and Diane Sconce with the Campbell Center in Eugene Recreation and Cultural Services enabled survey research with the 50+ age group of users. Tim Shearer and the staff and community at Lane Independent Living Alliance (LILA) contributed to this research by organizing individual ridealong observation sessions and providing final project feedback. Susan Hekimoglu and Cosette Rees from Lane Transit District (LTD) arranged a tour of buses at the central station and provided final project feedback.

\section{DISCLAIMER}

The contents of this report reflect the views of the authors, who are solely responsible for the facts and the accuracy of the material and information presented herein. This document is disseminated under the sponsorship of the U.S. Department of Transportation University Transportation Centers Program and the University of Oregon in the interest of information exchange. The U.S. Government and the University of Oregon assumes no liability for the contents or use thereof. The contents do not necessarily reflect the official views of the U.S. Government and the University of Oregon. This report does not constitute a standard, specification, or regulation.

\section{RECOMMENDED CITATION}

Faste, Trygve and Muenchinger, Kiersten. Design for an Aging Population. NITC-ED-986. Portland, OR: Transportation Research and Education Center (TREC), 2017. 



\section{TABLE OF CONTENTS}

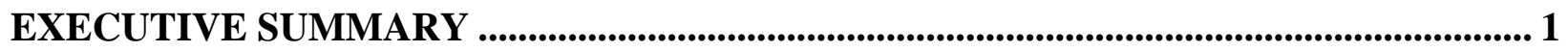

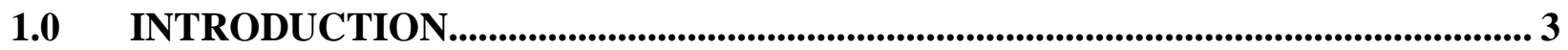

1.1 DIFFICULTY WITH PUBLIC TRANSPORTATION ................................................ 3

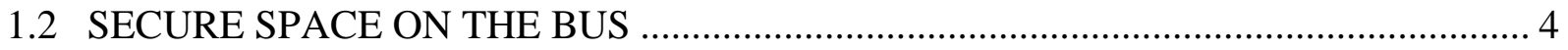

1.3 ASKING OTHERS FOR HELP ……………….................................................... 4

2.0 OBJECTIVE ................................................ERROR! BOOKMARK NOT DEFINED.

3.0 MATERIALS AND METHODS .....................ERROR! BOOKMARK NOT DEFINED.

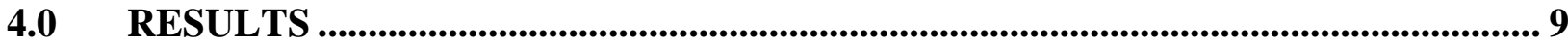

4.1 DIFFICULTY WITH PUBLIC TRANSPORTATION: THE CONCEPTUAL CHALLENGES TO BUS USE ......................................................... 9

4.2 SECURE SPACE ON THE BUS: THE PHYSICAL BARRIERS TO BUS USE.............. 9

4.3 ASKING OTHERS FOR HELP: THE SOCIAL COMPLICATIONS AND BARRIERS TO BUS USE ERROR! BOOKMARK NOT DEFINED.

5.0 DISCUSSION AND CONCLUSION .............. ERROR! BOOKMARK NOT DEFINED.

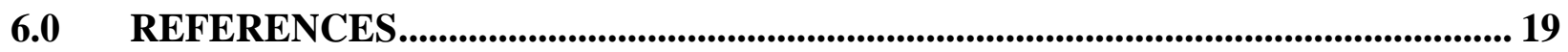

\section{LIST OF FIGURES}

Figure 4.1: Seating Sections of Ridership Among Users ………………………………........... 11

Figure 4.2: Model of People's Interpersonal Expectations on the Bus........................................... 13

Figure 5.1: Walker Designed to Integrate with Bus Seating ........................................................ 15

Figure 5.2: Fold-up Bus Seat with Secure Wall Bracket ……………………….......................... 16

Figure 5.3: WhMD Latch to Wall Bracket for Fold-up Bus Seat .................................................. 16 



\section{EXECUTIVE SUMMARY}

As the number of older Americans increases, so does the number of opportunities to design our built environment to better their lives. Older persons have limitations with vision, hearing and mobility with greater frequency and magnitude than the general population, so focusing on designs that aid these issues will provide older people greater opportunities to engage in their communities. Adults aged 65 and older find that using public buses is difficult for them, with problems including walking to and from bus stops and getting on and off a bus (Jansuwan, Christensen and Chen, 2013, 104-114). Once on the bus, finding a seat or spot can be both physically and emotionally threatening to older and disabled people. Proud and independent people also don't necessarily want to ask for help using the bus, finding a seat on the bus, or having their mobility device secured on a bus.

This study sought to increase understanding of these unique obstacles through applied product design methodology to generate qualitative research to better understand the complex dynamic around bus use and the elderly in a small city environment (Eugene, OR).

Surveys, one-on-one interviews, user observations, focus group sessions with elderly and disabled bus users, as well as interviews with transit experts were conducted by a group of design students at the University of Oregon, under the direction and guidance of Associate Professor Trygve Faste.

The results were that older riders had difficulty in three categories. Conceptual challenges to using the bus, where riders put off using the bus as long as possible due to the convenience of the car and the inconvenience of the bus. If an individual needs to stop driving for medical conditions, a common situation, then bus riding is all the more difficult. Walking to and from the bus stop was a mental as well as physical hurdle to overcome. Physical barriers to bus usage were due to slow and unsteady walking, and accessibility was physically difficult. The time it took to sit before the bus began moving made balance and proximity of seating key issues. This issue was complicated because, often, wheelchairs take up room in the priority seating area, seats need to flip up and down requiring manual effort, the front of the bus gets crowded with anyone who has bulky objects that don't fit in the back of the bus, and grab bars are not necessarily positioned correctly. Social complications and barriers to bus usage required older riders to have awkward social interactions more frequently than other riders, and included asking able-bodied riders to move from reserved seats, asking for help with seat folding, and asking others to request a stop or for the bus location. Every user group has a different set of expectations and assumptions about their fellow bus riders, which complicates the social dynamic.

There are many potential areas where thoughtful design solutions can eliminate many of the conceptual, physical and social problems that came up in the research. The student designers developed many concepts that illustrate possible solutions to these issues, from walkers that don't block the aisle, to self-latching wheelchairs, to digital seats that lock and unlock to reserve space for senior citizens at peak hours. 


\subsection{INTRODUCTION}

As the number of older Americans increases, so does the number of opportunities to design our built environment to better their lives. Because older persons have limitations with vision, hearing and mobility with greater frequency and magnitude than the general population, focusing on designs that aid vision, hearing and mobility in environments directed toward the public will provide older people greater opportunities to engage in their communities. Environments that support active transportation modes not only allow older people to maximize their physical activity but also their use of public transportation and, in turn, their engagement within the wider community (Zeitler et al.. 2012, 10). This study of the needs of people with vision, hearing and mobility issues in a public bus transportation system was instigated to synthesize existing research, discover new insights, and generate new designs that enhance the common use of public bus transportation.

The number of older people who are reliant on public transportation is increasing. There are jumps in the number of public transportation users as people hit ages 65, 75 and 85 (Frith, Mara and Langford, 2012; Gorti, 2004). A growing number of older Americans implies there will be a greater number of individuals relying on public transportation for a longer time period (Shaheen, Allen and Liu, 2010, 7-28). Disabled persons and people with medical conditions, who may have similar vision, hearing and mobility issues as those of older persons, also use public transportation more than the general population (Mattson, 2012; Penfold et al., 2008).

Nearly 20\% of Americans ages 65-74 identify themselves as having a condition that makes it difficult to travel, and that number increases to nearly 30\% for ages $75-84$ and increases again to 50\% for individuals aged 85 and above (Mattson. 2012). Medical conditions may impose physical constraints to travel, but they often do not curb people's desire to travel out of the home (Sikder and Pinjari, 2012, 137-147). While Americans want to drive their own cars as long as possible for the independence and flexibility personal car travel gives them, the likelihood that a person with a medical condition would give up driving increases significantly with age, from $28 \%$ of those $19-64$ to $62 \%$ of those 85 or older (Mattson, 2012).

\subsection{DIFFICULTY WITH PUBLIC TRANSPORTATION}

However, adults ages 65 and older find that using public buses is difficult for them, with problems including walking to and from bus stops and getting on and off a bus (Jansuwan, Christensen and Chen, 2013, 104-114). The ability to use one's personal mobility equipment throughout a journey is another problem experienced by disabled people (Penfold et al., 2008). Disabled persons cite the physical difficulties of using public transportation as a reason that travelling outside of the home is not merely difficult, but impossible ("Transportation difficulties keep over half a million disabled at home,” 2003). These findings would no doubt be very different in dense urban areas where parking is more challenging and more public transit options exist. 


\subsection{SECURE SPACE ON THE BUS}

Once on the bus, finding a seat or spot can be both physically and emotionally threatening to older and disabled people. Open seats, seats with reachable grab bars, and accessible spaces for walkers and wheelchairs may not be available on a given bus. The possibility of a seat not being available and needing to stand on the bus discourages some older people from attempting to ride the bus (Jansuwan, Christensen and Chen, 2013, 104-114). The seating areas that are designated for older and disabled persons may not be available or relinquished by other riders. For users of wheeled mobility devices (WhMD), including wheelchairs and motorized scooters, the strap systems available to secure the devices are not liked and are frequently not used (Gorti, 2004; Shaw and Gillispie, 2003, 309-319). This is understandable since these devices are not designed for securement in transit (Buning et al., 2007, 166-179), but there is a need for the development of Wheelchair Tiedown and Occupant Restraint Systems (WTORS) with improved usability (Gorti, 2004). As most of the reports of injuries to WhMD users are from non-collision incidents in which a WTORS user was inappropriately secured or an unrestrained rider was injured (Shaw and Gillispie, 2003, 309-319), restraints that provide security without meeting current collision standards may be appropriate for reducing typical rider injuries.

\subsection{ASKING OTHERS FOR HELP}

Proud and independent people also don't necessarily want to ask for help using the bus, finding a seat on the bus, or having their WhMD secured on a bus. Older people note that one of the benefits of using a bus is that they don't need to bother someone to get a ride (Frith, Mara and Langford, 2012). Finding additional ways bus transportation can provide moments of independence for older people may help their emotional health. Disabled persons cite not wanting to ask others for help as a reason that travelling outside of the home is impossible ("Transportation difficulties keep over half a million disabled at home," 2003), so helping the disabled traveler may also help her or his emotional health. Buning et al. reported that $39 \%$ of WhMD users never requested to have their WhMD secured during transit, and 49\% of respondents said they did not ask because either they or the bus driver did not want to take the time to secure the restraints (Buning et al., 2007, 166-179). A majority, 78\%, of participants would prefer to secure their own WhMD. Creating WTORS that can be operated independently by WhMD passengers is needed (Gorti, 2004; Frost, Bertocc and Salipur, 2013, 16-23) and is a way to provide moments of independence to all WhMD users 


\subsection{OBJECTIVE}

This study sought to increase understanding of the unique obstacles that people with impairments in vision, hearing and/or mobility face in using public bus transportation. These findings were used to aid in the design of products, structures and services that can reduce or eliminate these obstacles. By focusing on vision, hearing and mobility impairments, design solutions are applicable to older users, users with disabilities, and any other users who may have impairments or be in environments that cause impairments, like darkness or loud urban spaces. The driving goal is to improve bus transportation for our aging population, but the resulting ideas and services provide better public transportation for all. 


\subsection{MATERIALS AND METHODS}

This project applied product design methodology to generate qualitative research that can be used to better understand the complex dynamic around bus use and the elderly in a small city environment. The participants in this study include individuals who are aging and/or have mobility, vision and hearing challenges and who use the public bus system in Eugene, OR.

Nineteen surveys and seven one-on-one interviews conducted at the Campbell Center, a center for older citizens supported by Eugene Recreation Services, were conducted to document how bus riders aged 58 and older felt about public buses.

User observations while on a trip that utilized the bus were conducted to see how the current bus designs functioned for our sample population. Fifteen designers rode the Eugene bus system for three hours each, noting various challenges that arose for the elderly and disabled riders. Five ride-along observations, in which designers accompanied physically challenged older people, were subsequently conducted and documented.

In addition, two one-hour focus group sessions were conducted with active participants in the Lane County Independent Living Alliance (LILA). The 16 participants in these sessions were either public bus users with physical challenges, or professionals who help people with disabilities live independently.

Three experts on accessible public transportation in the Lane County Transit District (LTD), Eugene's public transportation authority, discussed their most pressing issues in interviews and during progress presentations for this project. 


\subsection{RESULTS}

\subsection{DIFFICULTY WITH PUBLIC TRANSPORTATION: THE CONCEPTUAL CHALLENGES TO BUS USAGE}

People drive themselves as long as possible. They appreciate the convenience of being able to travel more quickly and comfortably via car. Survey participants stated: "[My car is] convenient, faster, [and] better for running lots of errands" (77-year-old); "[Cars are] door to door all the way...car takes 7 minutes, and bus takes 35 to 50 minutes" (62-year-old); and "The bus can take 1 hour to go a 15-minute trip" (Campbell Center Survey). Though use of the bus was felt to be time consuming, of the surveyed riders $63 \%$ use the bus for running errands. This suggests that other factors make the inconvenience of the bus worthwhile.

Car preference goes beyond time efficiency. One 76-year-old participant shared that medical conditions complicate bus usage and driving is easier. "I have fibromyalgia and having a car means I don't have to walk so much. I know at some future time I am going to have to give up driving but I'm not looking forward to it.” Eventually people do stop driving when they have developed physical impairments. "I no longer drive [for] medical reasons." Similarly, one participant in Zeitler's research stated, "You can see why I push for a bus three/four times a week. There will come a time where I cannot drive anymore. How do I get to the shopping center?” (Zeitler et al., 2012, 10). Users who have always driven in their own cars may develop new disabilities, forcing them to become new to riding public transportation. Physical impairments also complicate getting to and from bus stops. "I walk from the bus stop home 1,200 steps up hill,” (Campbell Center Survey).

There were some aspects of riding the bus considered to be positive. "Comfortable - Safe - Good place to read a book" were some of the reasons a 69-year-old bus rider listed (Campbell Center Survey). In general, people considered the bus to be a safer than driving. One 66-year-old rider uses the bus “...when there is snow and ice.” Perceptions of safety and time are important considerations for older patrons when contemplating bus usage.

\subsection{SECURE SPACE ON THE BUS: THE PHYSICAL BARRIERS TO BUS USE}

People stop driving for medical reasons, so the accessibility of buses for the physically impaired is critical. In our survey of riders over the age of $58,47 \%$ use the bus due to impairments. Loss of mobility, sight and hearing are challenges to overcome, and physical environment within the bus becomes a critical component to its function as an enjoyable and viable transportation solution. Moving around the bus, sitting and standing are difficult for older bus riders. One 76year-old rider who has trouble getting on and off the bus due to balance issues states: "[The] driver should not start the bus until I'm seated," (Campbell Center Survey). While balance may be the most easily noticed issue, time is also a factor. One UK study found that older people walk 
slower than the $1.2 \mathrm{~m} / \mathrm{s}$ that the UK Department for Transport recommends as a baseline for crosswalk design. Only 11\% of older people kept this pace or above (Musselwhite, 2015, 44-61). Due to this slow rate of walking, the area in the front of the bus, most visible to the driver and the shortest distance from the front bus entrance, is desirable territory for older people.

Crowding can complicate the ability to sit quickly. One 72-year-old rider answered the question of how they felt about riding the bus stating, "It's too crowded" (Campbell Center Survey). An elderly rider noted that one annoyance is "people who put stuff on an adjacent seat when it could be in their lap." Built-in features of the bus can prevent older riders from accessing some sections. It was found that the steps between seating zones were too steep and that to enter the bus they had to use the front ramp. One rider stated, "I have fallen before boarding the bus because steps are too high," (Campbell Center Interview). Most buses have priority seating at the front as this area is quicker and easier to access. This zone is often full of people without disabilities because it affords space for bulky objects like luggage and baby strollers (Ride-along Observation). One man with a young child folded his stroller and sat in the priority seating area for people with disabilities with the stroller under the seat and the child on his lap when riding a small bus, but when he transferred to a larger bus with plenty of room in the back (a non-priority seating area where bicycles are usually stored), he kept the stroller unfolded in the aisle with the child sitting next to him (Ride-along Observation).

It was observed that the priority area in the front of the bus fills quickly with walkers that people do not fold up. The walker is needed for stability all the way to the rider's seat. The front of the bus is also the only place for riders using WhMDs, as it is designed such that they can be properly secured. On the observed buses, seats that could be used for elderly passengers often fold out of the way to fit wheelchairs; typically two attached seats fold up to make space for one wheelchair. If the two wheelchair bays are full, additional wheelchair users need to wait for another bus and elderly riders have four less priority seats to utilize. Bus riders may not be able to raise and lower the seats on their own due to the weight of the seat or complexity of the latching mechanism. It is very hard to move the seats in the priority seating area up or down. This creates even more demand on an already-burdened area of the bus. Better seat designs do exist but were not present on these ride-along observations, highlighting the challenges of implementing good solutions.

While the front of the bus is designed for highest-priority seating availability, one rider stated: "I don't actually sit in the handicapped spot, I like to sit next to a certain seat with better railings," (Campbell Center Interview). Another older rider who prefers a particular seat on the bus as it is the only seat with a nearby slanted grab bar what she likes: "I always want to sit here because then I can lower myself into the seat, it is way better. I wish every seat had a way to lower like this," (Ride-along Observation). Prior research has shown that "[t]he greatest problem and safety hazard within independent home environments for the elderly with limited mobility is the absence of grab bars," (Chappell and Cooke, 2010). This research confirms the need for wellplaced grab bars in moving environments, as it was observed that many people with varying levels of disabilities were using the ramps and rails for supports. 


\subsection{ASKING OTHERS FOR HELP: SOCIAL COMPLICATIONS AND BARRIERS TO BUS USE}

Older and disabled bus patrons need to interact with other passengers or the bus driver more frequently and in different ways than other riders. A diagram showing four overlapping areas of social interaction between various bus occupants can be seen in Figure 4.1.

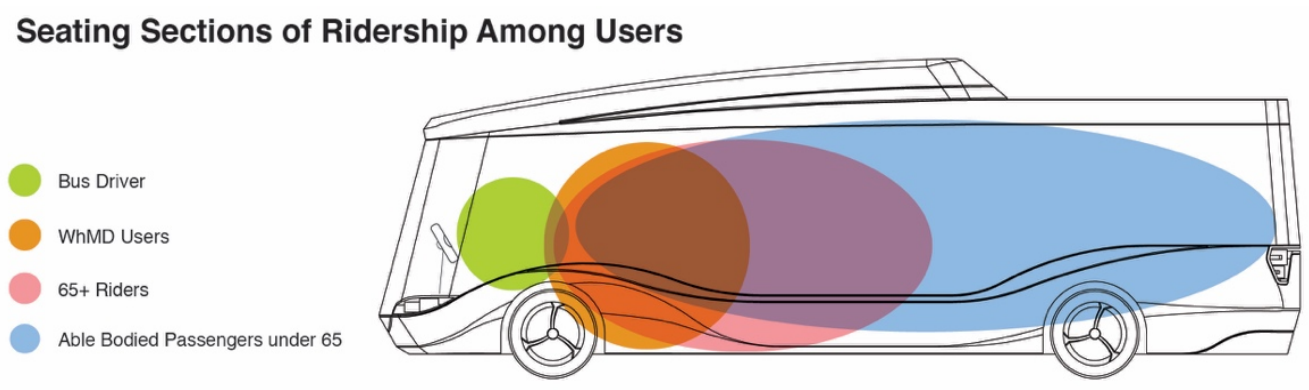

Figure 4.1: Seating Sections of Ridership Among Users (Faste)

One contributing factor to increased interaction is the crowded reserved seating area (Ride-along Observation). If the seats are being used by non-disabled riders who do not move of their own accord, an older or disabled rider must ask them to move if they wish to sit. People expressed frustration with bus etiquette during the LILA focus group sessions. It was also found that though people with disabilities are willing to accept help, they like to feel self-sufficient and would rather be able to board and exit the bus without assistance. Bus users conveyed that they enjoyed the freedom from their caretakers that the bus provides, and that asking others to move is counterproductive to feeling independent.

Other ways that riders who are older and/or disabled may be forced to ask for special assistance involves knowing when they have reached their destination. One user with vision impairments stated: "I have to memorize all of my routes because the speakers don't announce every stop so I can't hear them at all sometimes," (LILA Focus Group). When this rider loses count they have to ask where they are. Other riders find it difficult or impossible to reach the pull cord or button to indicate their desire to disembark at the next stop. This requires that they call attention to themselves by either yelling to the bus driver that they would like to stop, or by asking a stranger to pull the cord (Ride-along Observation). On the buses observed, the button designed for wheelchairs to request a stop is actually very difficult to reach, so people in wheelchairs often have to remind the bus driver to help them get unstrapped or to get the ramp out (LILA Focus Group). Catching the right bus is also difficult. "I can't see my bus and so I just have to memorize my stops and hold this card and hope that the driver can see me,” (LILA Focus Group). This user is blind, and the cards with numbers indicate which bus she needs to catch when she is waiting at a stop that multiple buses pass.

These observations indicate that the bus driver is asked to assist in many situations. Drivers have a lot of other factors to consider, including driving the bus, collecting bus fares, answering questions, noticing when people have reached their seat, and helping strap in/out wheelchairs (Ride-along Observation). The straps used to secure wheelchairs don't work on all wheelchairs, and are low and out of reach (LILA Focus Group). The messy appearance of these straps doesn't help riders feel safe, and many times require driver assistance to use properly. One bus driver 
waited to help strap in and unstrap a wheelchair user in the hope that some other rider would do so voluntarily (Ride-along Observation). He was thankful to the person who did help, suggesting he really appreciated having his workload lightened. Drivers also don't always want to stop and do the work required to strap in a wheelchair (LILA Focus Group). The drivers will typically release people from the straps more often than helping them put on the straps. This leads to a potentially awkward social situation where, if the driver does not engage with the WhMD user, the WhMD user has to ask a stranger for help. In this situation, riders would have to notice that nobody else is helping, and then work together to figure out what to do. While this is a seemingly plausible solution to the problem of an overly burdened driver, it has a few potential drawbacks. One is that the person being helped may feel self-conscious about their reliance on the kindness of strangers, a potential blow to self-esteem. Another is that the person helping may not know the safe and correct way to operate the equipment. Instructions on how to strap in a wheelchair are difficult to read (Ride-along Observation). On the other hand, social interactions can be a positive experience, and $26 \%$ of the survey participants mentioned that they enjoyed interacting with friendly bus drivers. Similarly, successful transportation programs for older people in some communities are considered to include the driver's kindness and general demeanor with older persons (Berliner et al., 2014). The various and complex social expectations of the bus driver, riders under 65, riders older than 65 and WhMD users is summarized in Figure 4.2, and shows the great potential for awkward or frustrating interactions. 


\section{What People Expect of Each Other on the Bus}

When these expectations are not met, confusion and frustration can occur
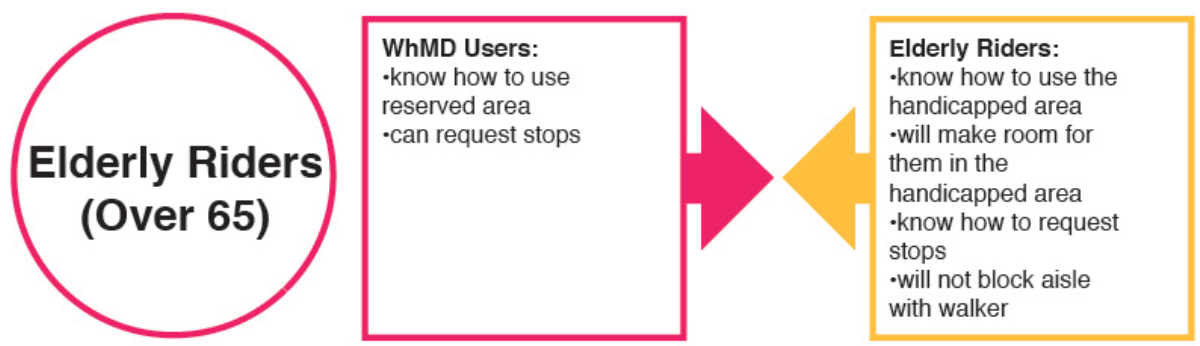

Able bodied Riders: -should help them with seating

- give up their seat for them or move for them -help them request stops and ramps

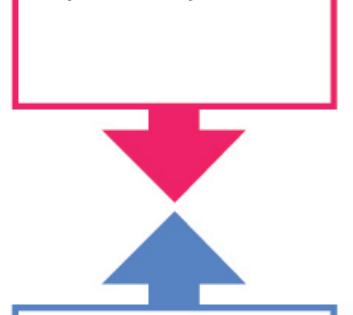

Elderly Riders: -know how to board on their own

-secure themselves -find a seat -notify bus driver of a stop
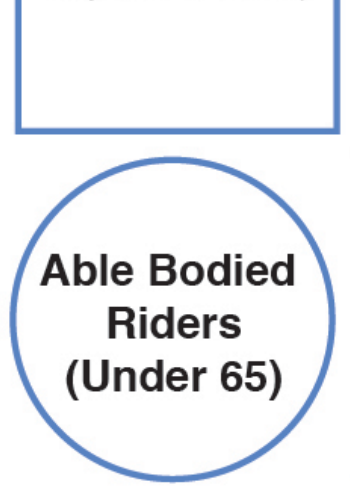

Bus Drivers:

-open the ramp for them when they need it

-help them with seating

-wait to drive until they are seated

-get to know them, talk with them

-stop when requested -drive safely
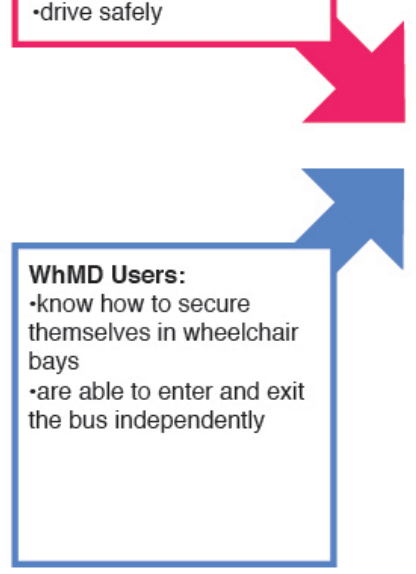

Bus Drivers:

-help WhMD riders and elderly riders boarding and seating

Figure 4.2: Model of People’s Interpersonal Expectations on the Bus (Faste) 


\subsection{DISCUSSION AND CONCLUSION}

This research shows that as people age they face conceptual, physical and social barriers that impact their willingness to use buses as a viable means of transportation. While people born with disabilities were motivated to use public transportation and the independence that it provided (LILA Focus Group), aging people saw their cars as supplying more independence and the bus to be limiting (Campbell Center Survey and Campbell Center Interview). As a result, the needs of elderly riders, which may be less physically obvious than those of WhMD users or riders with product clues to their disabilities, must be successfully addressed through thoughtful design to increase ridership.

Convenience to easily accessible seats and secure WhMD stations at the front of the bus is critical for older users, as it makes riding the bus less draining and more safe. Many older riders use walkers to help them all the way to their seats (Ride-along Observations). Currently, walkers block aisles and do not otherwise integrate with bus seating. Because the front of the bus is also used for large objects like luggage and strollers, there is a concentration of non-secured, wheeled, bulky objects localized where people with physical impairments sit. It is highly likely that increased obstacles like this make moving more challenging for people who need to sit in this area, and may lead to an increased risk of accidents.

Designing walkers that can comfortably traverse the variety of terrains an elderly person encounters from their doorstep to a bus seat has great potential. If walkers also took into account bus seat design and the interior architecture of the bus, they could provide user stability and minimize aisle obstruction to create a safer and more efficient use of the priority seating space. In addition, if the interior of the bus were redesigned in concert with the walker, the walker-user would have a more harmonious bus-riding experience (Figure 5.1). 


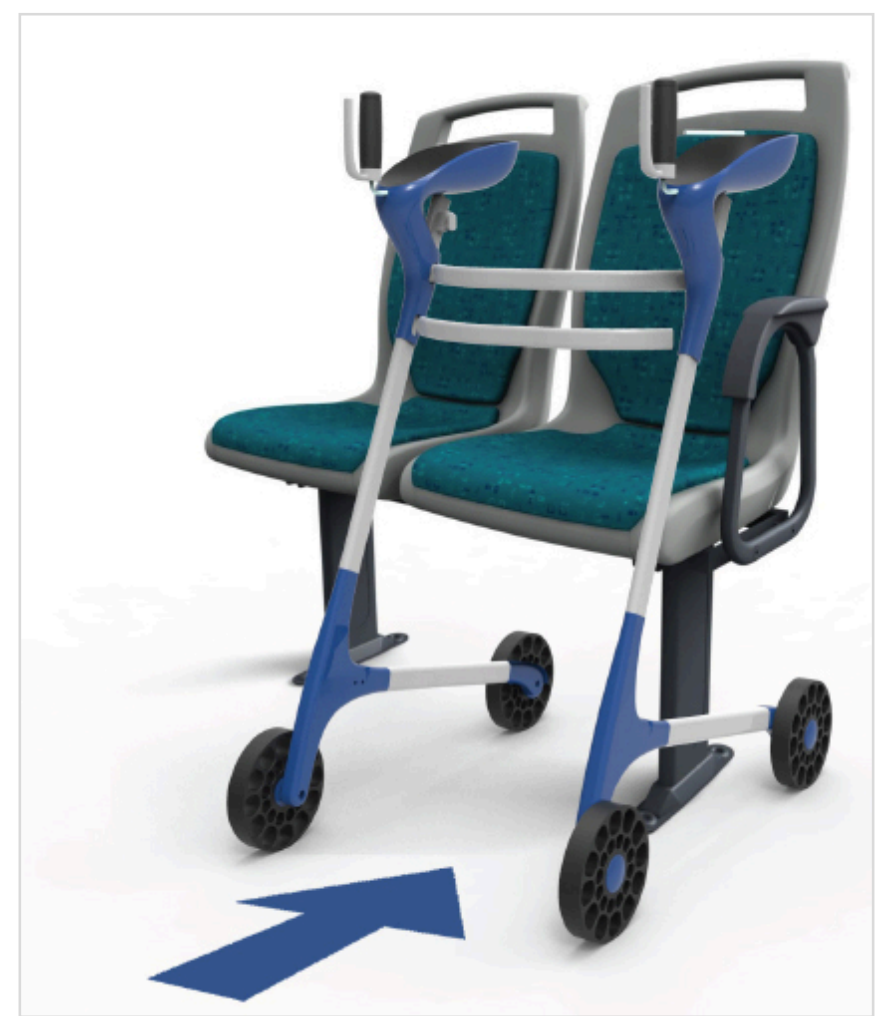

Figure 5.1: Walker Designed to Integrate with Bus Seating (Keyes and Koby)

The many different types of riders in priority seating areas pose a wide array of competing needs. One such conflict is that an older person wants an empty chair to be there when they enter the bus, whereas a person in a wheelchair wants a chair not to be there when they enter the bus (Ride-along Observations). Both needs should be met in better ways than the current folding systems offers. As each bus is different, figuring out how to operate the heavy folding seats, different types of latches and the wheelchair restraints can be confusing. Negotiating between all of the users' needs to ensure reliable seating for prioritized passengers is another area where thoughtful design can make a significant impact.

Currently, the WTORS and the seats are two separate designs. Integrating WTORS and seats into one design that transitions seamlessly from seat to wheelchair mount would be a powerful innovation. One study found that low-g events from the bus braking or turning occur frequently and account for half of onboard passenger injuries and, in the study, account for all of the wheelchair riders' fatal and nonfatal injuries. This result implies that WTORS that sacrifice highg protection for improved ease of use could reduce injury risk significantly (Shaw, 2008, 85108). A system of seats that flip up (as in a movie theater) in order to offer a secure wheelchairlocking bracket is one strategy (Figure 5.2). With this concept any seat could potentially secure a wheelchair, which adds flexibility to the bus layout. Each WhMD would have standard latches, like those found inside car doors, that mount into the existing WhMD hitches (Figure 5.3). This concept builds on the device of Hunter-Zaworski, whose research concluded that though there are engineering challenges to overcome, a self-latching system for WhMDs on public buses is viable (Hunter-Zaworski, Zaworski and Clarke, 1992). The WhMD user may attach herself by backing up to the bracket until the latch mechanism locks to the seat bar, and detach through a 
release switch mounted on her WhMD. The ease of use of a universal wheelchair coupling system could increase overall bus capacity for WhMDs, increase the number of secured wheelchairs on buses and potentially lower the number of low-g accidents.

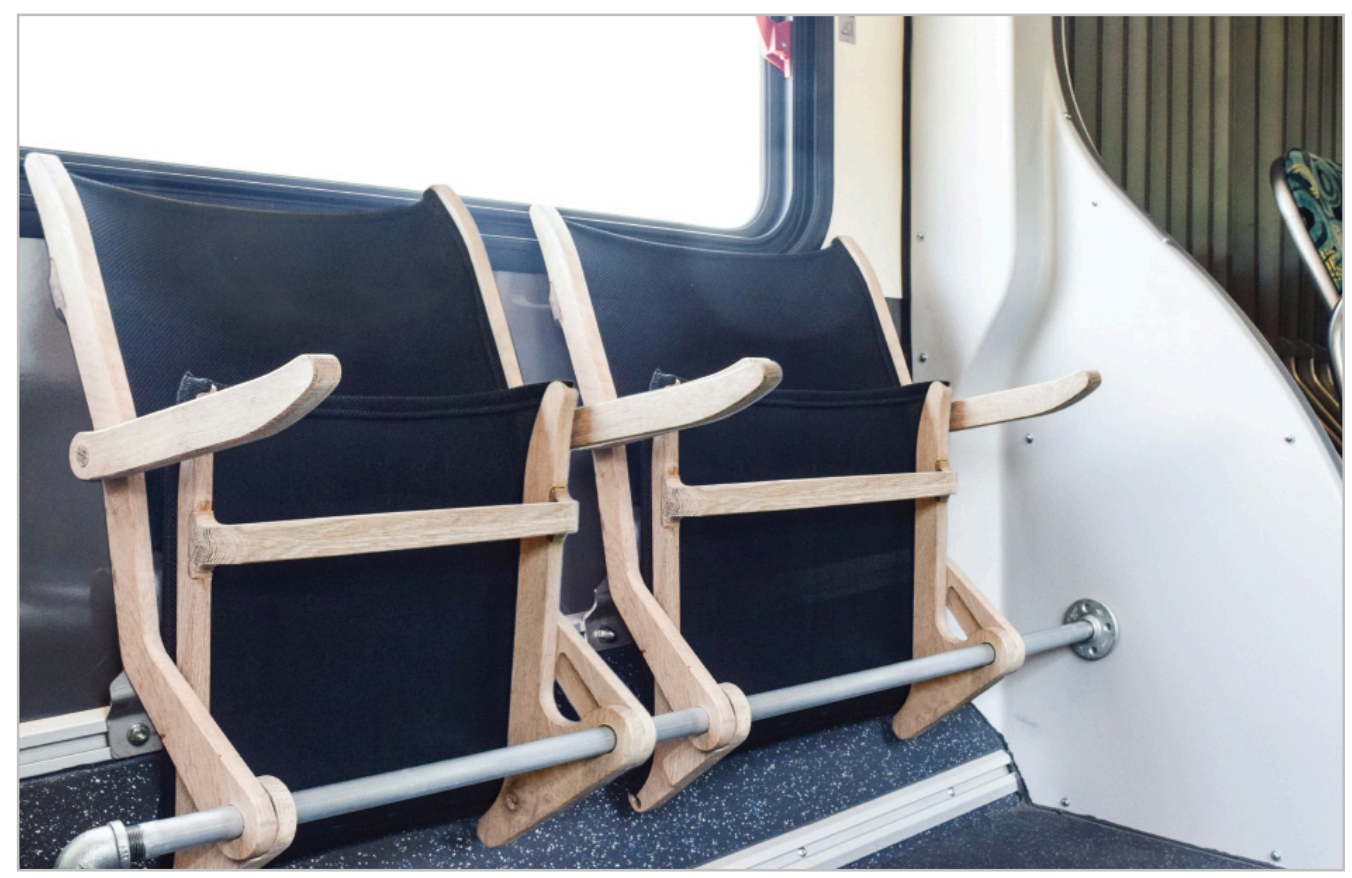

Figure 5.2: Fold-up Bus Seat with Secure Wall Bracket (Tuttle)

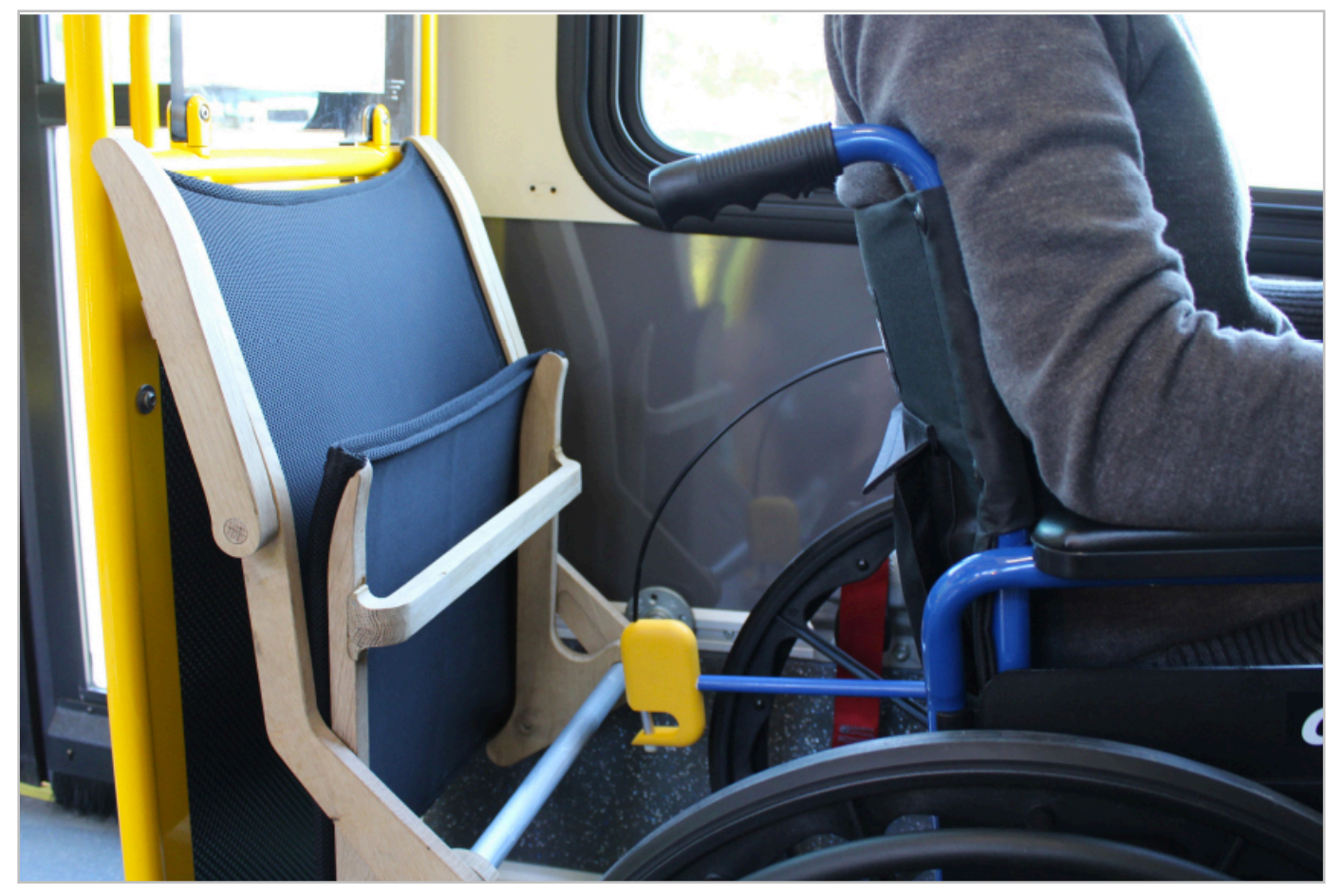

Figure 5.3: WhMD Latch to Wall Bracket for Fold-up Bus Seat (Tuttle) 
Folding priority seats could be "smart" programmed to lock in the closed position until a senior citizen enters the bus. The senior citizen bus pass could have an RFID tag that would wirelessly communicate with the seat, similar to a security tag and detector system at a department store. A reserved seating system affords an older rider some of the convenience they lost when they stopped using their own car. Such a system could be optimized to take into account ridership patterns, and would know when older riders need more seating reserved. While this system could be controlled by software, the bus driver could also have an override if needed. This coordinated system ensures that a seat is already flipped up, out of the way, when a WhMD user enters the bus and comes to clip into the seat bar.

A system similar to the one described above that can supply seats when needed and remove them when not needed would also address the social awkwardness elicited by the current system. It addresses the availability, flexibility, security, convenience and spontaneity attributes noted by Coughlin (2001) to be desired in transportation to service older persons. Bus drivers would no longer need to help buckle in WTORS users, eliminating an extra responsibility and giving them more time to focus on other tasks. Older people would no longer need to ask other bus patrons to move so that they can sit, and able-bodied people would not be confused as to where they should sit. All riders would have a heightened sense of independence and understanding of bus etiquette.

Simple designs could also aid independence for people with visual and auditory impairments. A small fob (such as a key fob for a car) could tap into a GPS system on the bus, and at the touch of a button could inform riders of their position via text or voice recording or signal the bus driver that a stop is requested. A product like this would also greatly assist users who can't reach the stop request cable, reducing the need for them to shout to the driver. The product could be supplied by the bus system on request, and returned when no longer needed. Though the cost could be an initial barrier, the added efficiency could help to improve the riding experience for both passengers and drivers.

As discussed, this project generated many potentially viable design solutions to the conceptual, physical and social aspects of riding public buses encountered by persons who are older or disabled. These design concepts illustrate the importance of synthesizing research with creative process. The prototype designs require further testing and refinement. With appropriate development, innovations that take into account the needs of vision-, hearing- and mobilitychallenged people can make bus riding more intuitive and enjoyable for the aging bus riders and the community as a whole. 


\subsection{REFERENCES}

Berliner, R., E. Swansen, M. A. Knodler Jr., S. Tupper, D. Peabody, and J. Collura. “The Complex Web of Senior Mobility Services.” TRB 93rd Annual Meeting Compendium of Papers. 2014.

Buning, M. E., C. A. Getchell, G. E. Bertocci, and S. G. Fitzgerald. "Riding a bus while seated in a wheelchair: A pilot study of attitudes and behavior regarding safety practices.” Assistive Technology 19: 166-179. 2007.

Bureau of Transportation Statistics (BTS). "Transportation difficulties keep over half a million disabled at home.” BTS Issue Brief No. 3: 1. Dept. of Transportation, Washington, DC. 2003.

Chappell N.L., and H. A. Cooke. “Age Related Disabilities - Aging and Quality of Life.” In International Encyclopedia of Rehabilitation edited by JH Stone, and M Blouin. Accessed April 14, 2015. http://cirrie.buffalo.edu/encyclopedia/en/article/189/ . 2010.

Coughlin, J. “Transportation and Older Persons: Perceptions and Preferences.” A Report on Focus Groups. Centre for Transportation Studies and Age Lab, AARP. 2001.

Frith, W., M. K. Mara, and J. Langford. 2012. "Demand for transport services: impact on networks of older persons' travel as the population of New Zealand ages.” New Zealand Transport Agency. 2012.

Frost, K. L., G. Bertocc, and Z. Salipur. "Wheelchair securement and occupant restraint system (WTORS) practices in public transit buses.” Assistive Technology 25: 16-23. 2013.

Gorti, R. K. "An analysis of travel trends of the elderly and zero-vehicle households in the United States.” MSci thesis. Civil Engineering, Department of Civil and Environmental Engineering, University of South Florida, Tampa, FL. 2004.

Hunter-Zaworski, K., J. Zaworski, and G. Clarke. “The Development of an Independent Locking Securement System for Mobility Aids on Public Transportation Vehicles.” US Department of Transportation. 1992.

Jansuwan, S., K. Christensen, and A. Chen. "Assessing the Transportation Needs of Low Mobility Individuals: Case Study of a Small Urban Community in Utah.” Journal of Urban Planning and Development 139 (2): 104-114. 2013.

Mattson, J. “Travel Behavior and Mobility of Transportation-Disadvantaged Populations: Evidence from the National Household Travel Survey.” Upper Great Plains Transportation Institute. Accessed April 14, 2015. http://www.ugpti.org/pubs/pdf/DP258.pdf. 2012. 
Musselwhite, C. "Environment-person interactions enabling walking in later life.” Transportation Planning and Technology 38 (1): 44-61. 2015.

Penfold, C., N. Cleghorn, C. Creegan, H. Neil, and S. Webster. “Travel behaviour, experiences and aspirations of disabled people.” Report for Dept. of Transport United Kingdom, National Centre for Social Research (NatCen), London. 2008.

Shaheen, S., D. Allen, and J. Liu. "Public Transit Training: A Mechanism to Increase Ridership Among Older Adults.” Journal of the Transportation Research Forum, 49 (2): 7-28. 2010.

Shaw, G. "Investigation of large transit vehicle accidents and establishing appropriate protection for wheelchair riders.” Journal of Rehabilitation Research and Development 45: 85-108. 2008.

Shaw, G., and T. Gillispie. "Appropriate protection for wheelchair riders on public transit buses.” Journal of Rehabilitation Research and Development 40: 309-319. 2003.

Sikder, S., and A. R. Pinjari. "Immobility Levels and Mobility Preferences of the Elderly in the United States: Evidence from 2009 National Household Travel Survey.” Transportation Research Record: Journal of the Transportation Research Board 2318: 137-147. 2012.

Zeitler, E., L. Buys, R. Aird, and E. Miller. "Mobility and Active Ageing in Suburban Environments: Findings from In-Depth Interviews and Person-Based GPS Tracking.” Current Gerontology and Geriatrics Research. 2012: 10. 
Transportation Research and Education Center

Portland State University

1900 S.W. Fourth Ave., Suite 175

Portland, OR 97201 